\title{
Four Failures to Demonstrate that Scarcity Magnifies Preference for Familiarity
}

\author{
Stephen Antonoplis \\ University of California, Berkeley \\ Serena Chen \\ University of California, Berkeley
}

\begin{abstract}
As economic inequality increases in the United States and around the world, psychologists have begun to study how the psychological experience of scarcity impacts people's decision making. Recent work in psychology suggests that scarcity - the experience of having insufficient resources to accomplish a goal-makes people more strongly prefer what they already like relative to what they already dislike or like less. That is, scarcity may polarize preferences. One common preference is the preference for familiarity: the systematic liking of more often experienced stimuli, compared to less often experienced stimuli. Across four studies - three experiments and one cross-sectional survey (all pre-registered; see https://osf.io/7zyfr/) — we investigated whether scarcity polarizes the preference for familiarity. Despite consistently replicating people's preference for the familiar, we consistently failed to show that scarcity increased the degree to which people preferred the familiar to the unfamiliar. We discuss these results in light of recent failures to replicate famous findings in the scarcity literature.
\end{abstract}

Keywords: Scarcity, Familiarity, Open Science

With economic inequality rising markedly since the 1980s, and especially since the 2007 global recession (Piketty, 2014), scholars from various fields have turned their attention to understanding the effects of scarcity on human psychology. A growing approach to this question investigates the impact of the psychological experience of scarcity on thoughts, feelings, and behaviors. In this file drawer report, we sought to understand the impact of scarcity on the familiarity bias, the systematic liking of more familiar, compared to less familiar, stimuli (Zajonc, 1968).

\section{What is Scarcity?}

Scarcity is defined as a lack of sufficient resources for accomplishing a goal (Shah, Mullainathan, \& Shafir, 2012). Research has found that it increases overborrowing and focus on the present (Shah et al., 2012; Shah, Mullainathan, \& Shafir, 2018); increases the propensity to lie in order to secure financial rewards (Gino \& Pierce, 2009); and increases the likelihood of taking risks and the quickness to approach temptations if participants grew up in a lower social class (Griskevicius et al., 2013). Importantly, the resources for which a person experiences scarcity can be of many different forms, and the form of the resources (e.g., time or money) is not thought to change the effects of scarcity on human psychology (Mullainathan \& Shafir, 2013). For instance, both time and material scarcity have been found to increase overborrowing in the present (Shah et al., 2012; Shah et al., 2018).

Most pertinent to the present research, recent research suggests that scarcity polarizes preferences (Zhu \& Ratner, 2015). When offered a choice between various products, participants more strongly preferred their favorite (vs. nonfavorite) option when few of each option were available (scarcity) versus when many were available (abundance). This occurred because scarcity was perceived as threatening, inducing higher arousal, which has been previously shown to polarize people's preferences (e.g., Gorn et al., 2001; Mano, 1992, 1994). Below, we propose that this effect may extend to the preference for familiarity.

\section{The Familiarity Bias}




\section{ANTONOPLIS \& CHEN}

Familiarity bias refers to the systematic preference for more familiar stimuli over less familiar stimuli, where familiarity is defined as frequency of exposure. In other words, familiarity bias describes the phenomenon that people tend to like things they have been exposed to more often simply because of the rate of exposure (Zajonc, 1968). Many classic studies in psychology suggest that people normatively prefer more, to less, familiar stimuli. For instance, research on the mere exposure effect has shown that individuals rate stimuli more positively if the stimuli occur more versus less frequently in the participants' natural environment, as well as if the stimuli resemble more versus less closely other stimuli in participants' natural environment (e.g., Johnson, Thomson, \& Frincke, 1960; Zajonc, 1968, 2001). Familiarity bias has been shown across many kinds of stimuli, including fruit and vegetables (Zajonc, 1968), nonsense syllables (Johnson et al., 1960), and people's names (Oppenheimer, 2004). Two metaanalyses have examined the robustness of the phenomenon. Across 208 experiments, Bornstein (1989) found the effect to be quite reliable, although the impact of publication bias on the results was difficult to assess due to a lack of adequate tests for assessing these effects at the time the meta-analysis was conducted. (Montoya et al., 2017) built on Bornstein's (1989) meta-analysis and found that the effect was reliable across 118 studies and, using more appropriate tests, that publication bias likely did not bias the estimates. Thus, a large body of research indicates that people, in general, prefer more to less familiar objects. How might the psychological experience of scarcity alter this preference? Below, we suggest that scarcity may magnify people's preference for familiarity, making people more strongly prefer familiarity under scarcity than not under scarcity.

\section{Does Scarcity Increase the Familiarity Bias?}

Recent research suggests that scarcity polarizes preferences (Zhu \& Ratner, 2015). When offered a choice between various products, participants more strongly preferred their favorite (vs. non-favorite) option when few of each option were available (scarcity) versus when many were available (abundance). The researchers argued that this occurred because scarcity was perceived as threatening, inducing higher arousal, which has been previously shown to polarize people's preferences (e.g., Gorn et al., 2001; Mano, 1992, 1994). When participants experienced scarcity (here, of quantity), they felt threatened by it. This threat increased their arousal, which restricted the number of evaluative dimensions considered relevant to the decision. One dimension, prior liking, was deemed particularly relevant to the decision, perhaps because threat constitutes a negative affective experience and people experiencing negative affect often choose simple decision strategies (Mano, 1994). Finally, to determine their preferences, participants more heavily relied on this single dimension of prior liking, producing more polarized preferences than would have resulted if other, imperfectly correlated dimensions had been incorporated into the decision.

Applied to the familiarity bias, such theorizing suggests that, when experiencing scarcity, people will feel more threatened and aroused, causing them to use simpler decision strategies. Because the familiarity bias is a common phenomenon (Bornstein, 1989; Montoya et al., 2017; Zajonc, 1968, 2001) and familiarity is a simple judgment to make (e.g., Glaze, 1928), people may rely on familiarity of stimuli to guide their choices. As familiarity already breeds liking (Zajonc, 1968), relying predominantly on familiarity in a decision task should increase stratification along familiarity. In other words, people should come to more strongly prefer familiar stimuli, relative to less familiar stimuli, under scarcity. In addition, since scarcity is expected to impact people similarly, regardless of its form (Mullainathan \& Shafir, 2013), the effect should appear across any form of scarcity (e.g., material, time, quantity). Hence, in this file drawer report, we examined the effect of different forms of scarcity (material, time, and quantity) on the familiarity bias.

\section{The Present Research}

Across four studies we tested whether scarcity, in various forms, amplifies individuals' preference for familiar over unfamiliar stimuli. We aimed to show that this pattern was consistent across various kinds of more versus less familiar stimuli. Key to note is that the studies by Zhu and Ratner (2015), which we based ours on, took an idiographic approach to measuring preferences, examining changes in each participant's favorite and non-favorite options. All of the work they cited in support of the hypothesized link between scarcity and preferences took a nomothetic approach (e.g., more vs. less risky options in terms of normative probability; Gorn et al., 2001; Mano, 1992, 1994). In line with this, the authors speculated that their hypothesis would hold using a nomothetic approach (p. 12, Zhu \& Ratner, 2015). Hence, in the present studies, we tested the effect of scarcity on nomothetic preference for familiarity. This work, then, should be understood as a generalizability test of the work presented by Zhu and Ratner (2015), rather than a replication (LeBel et al., 2019). In addition, some of our studies, unlike those of Zhu and Ratner (2015) used an incidental manipulation of scarcity, in which the experience of scarcity was not incorporated into the same situation or context as the assessment of preference. As others have argued (Bargh, 1992), incidental versus explicit manipulation of social psychological phenomena is not crucial to studying the phenomena. What is crucial is that manipulations bring to mind whatever concept (in this case, scarcity) is of interest, thereby allowing this concept to shape how subsequent stimuli are perceived. Thus, social psychological research on scarcity has been able to use 
incidental manipulations of scarcity without issue (e.g., Roux et al., 2015).

For all studies, we pre-registered focal hypotheses, data exclusion criteria, statistical modeling, and dependent and independent variables on the Open Science Framework (available at https://osf.io/7zyfr/). This report is an exhaustive report on all data available from research projects relating to the topic, where at least one of the authors was principal investigator, or have otherwise the right to publish the results. This includes not only null findings, or unexpected findings, but also studies that are suspected to have failed, with careful explanation of the circumstances of the failure (e.g., experimental error, failed manipulation check). The context surrounding how these data were collected, and if they are somehow connected to already published studies (e.g., dropped experiments) is carefully explained. We report how we determined our sample sizes, all data exclusions, and all measures in all studies. All analyses were conducted in $\mathrm{R}$ (version 3.6.2; $\mathrm{R}$ Core Team, 2019). Finally, to improve the paper's narrative, we report studies differently than the chronological order in which they were conducted.

\section{Study 1}

For the initial test of our hypothesis, we sought to combine methods from both the scarcity and familiarity bias literatures in order to use non-controversial, reliable methods. To manipulate scarcity, we had people recall a time they experienced scarcity (cf. Roux et al., 2015; Mani et al., 2013).To measure preference for familiarity, participants rated how much they liked both familiar and unfamiliar given names and surnames (cf. Oppenheimer, 2004), as well as nonsense syllables (cf. Johnson et al., 1960). The key test of our hypothesis was whether the scarcity manipulation moderated participants' preference for familiarity such that this preference was heightened under scarcity. The preregistration form, study materials, and data are available here: https://osf.io/7vtqr/.

\section{Method}

Following an informal lab policy of collecting 100 participants per between-subjects condition, two hundred and one participants were recruited from Amazon's Mechanical Turk. Their demographic characteristics matched typical samples on MTurk

Table 1

Demographics Across All Studies (Proportions and Means)

\begin{tabular}{|c|c|c|c|c|}
\hline \multirow[b]{3}{*}{ Gender } & \multicolumn{4}{|c|}{ Study } \\
\hline & Study 1 & Study 2 & Study 3 & Study 4 \\
\hline & & & & \\
\hline Man & .50 & .61 & .46 & .50 \\
\hline Woman & .27 & .39 & .53 & .50 \\
\hline Transgender & .00 & .00 & .004 & .00 \\
\hline Decline to State & .23 & .00 & .004 & .00 \\
\hline \multicolumn{5}{|l|}{ Race } \\
\hline White & .77 & .75 & .78 & .67 \\
\hline Latinx/Hispanic & .06 & .05 & .08 & .11 \\
\hline Black & .09 & .08 & .05 & .10 \\
\hline Native American & .00 & .02 & .00 & .00 \\
\hline Asian & .06 & .11 & .06 & .00 \\
\hline Middle Eastern & .00 & .00 & .00 & .00 \\
\hline Mixed & .01 & .00 & .04 & .02 \\
\hline Other & .00 & .00 & .00 & .04 \\
\hline Decline to State & .02 & .00 & .00 & .00 \\
\hline
\end{tabular}

Born in the U.S. 


\begin{tabular}{|c|c|c|c|c|}
\hline \multicolumn{5}{|c|}{ ANTONOPLIS \& ChEN } \\
\hline Yes & .83 & .98 & .94 & - \\
\hline No & .00 & .02 & .05 & - \\
\hline Decline to State & .17 & .00 & .01 & - \\
\hline Age $(M, S D)$ & $\begin{array}{c}39.30 \\
(10.97)\end{array}$ & $\begin{array}{l}33.64 \\
(9.58)\end{array}$ & $\begin{array}{c}36.91 \\
(11.66)\end{array}$ & $\begin{array}{c}50.19 \\
(16.72)\end{array}$ \\
\hline ncome $(M, S D)$ & $\begin{array}{c}\$ 38,130 \\
(\$ 25,871)\end{array}$ & $\begin{array}{c}\$ 36,093 \\
(\$ 21,684)\end{array}$ & $\begin{array}{c}\$ 38,643 \\
(\$ 29,447)\end{array}$ & $\begin{array}{c}\$ 72,053 \\
(\$ 47,986)\end{array}$ \\
\hline
\end{tabular}

\section{Education}

\begin{tabular}{rcccc} 
High School or Less & .13 & .14 & .12 & .41 \\
At Least & .86 & .86 & .88 & .59 \\
$\begin{array}{r}\text { Some College } \\
\text { Decline to State }\end{array}$ & .02 & .00 & .00 & .00 \\
\hline
\end{tabular}

Note. "-_ indicates that an item was not administered in the dataset. With the exceptions of age and income, all numbers in cells are proportions.

(mostly White, mostly men, in their mid-30's, had some amount of college education, and earning a relatively low income; Buhrmester et al., 2011) and are reported in full in Table 1. Participants were randomly assigned to a scarcity or control condition. In the scarcity condition, participants wrote about a time they felt their resources were scarce (i.e., did not meet their needs; taken from Roux et al., 2015). We expected writing about an experience of scarcity to be affectively unpleasant, but we expected its effects would be driven by the induction of threat, rather than negative affect more generally. Hence, to rule out negative affect as an alternative explanation, participants in the control condition wrote about a recent negative experience.

After writing about a negative or scarcity experience, participants rated how much they liked eight female given names (four familiar, four unfamiliar), eight male given names (four familiar, four unfamiliar), and eight surnames (four familiar, four unfamiliar). Participants also rated how good or bad they thought the meanings of twenty-four nonsense syllables were in a foreign language. All names were rated on a scale from 1 (=dislike) to 7 (=like). All nonsense syllables were rated on a scale from $1(=b a d)$ to 7 $(=$ good $)$. Participants were randomly assigned to either rate all the names first and the syllables second, or the syllables first and all the names second. This was done to avoid order effects. Although the use of an incidental manipulation indirectly related to the dependent variable might seem problematic for ecological validity, this practice is fairly common in the scarcity (e.g., Mani et al., 2013) and familiarity bias literatures (e.g., Muthukrishnan et al., 2009).

Female and male given names were taken from the 2016 US Social Security Registry of Baby names (available at https://names.mongabay.com/female_names.htm for female names and https://names.mongabay.com/male_names.htm for male names). For each gender, we selected four names from the top twenty most common as the familiar names (females: Isabella, Sophia, Emma, Olivia; males: Jacob, Ethan, Michael, William) and four names from the bottom twenty of the top 1000 (i.e., names 981-1000) as the unfamiliar names (females: Lilith, Charleigh, Dania, Savannah; males: Truman, Eliezer, Reuben, Bailey). We chose names from the top and bottom of the top 1000 to make sure that the frequencies of the names varied and that all names were somewhat recognizable (i.e., to avoid outlier names). We used this same process to select surnames, though names were pulled from the most recent (2010) US Census instead of Social Security data (familiar: Smith, Johnson, Williams, Brown; unfamiliar: Galloway, Bray, Nieves, Petty; data available at https://www.census.gov/topics/population/genealogy/data/2 010_surnames.html). We used names as stimuli because prior work had obtained familiarity effects using names (Oppenheimer, 2004).

The nonsense syllables were taken from Study 3 by Johnson et al. (1960). They found that syllables obtaining low $(0 \%)$, medium $(47-53 \%)$, and high $(100 \%)$ rates of judged association with English words (in Glaze, 1928) were thought to have better (i.e., more "good") meanings when participants were told the syllables were words from foreign languages and then judged how much the words referred to "good" or "bad" things. Glaze (1928) obtained the syllables' associations with English words by asking 15 participants whether they could quickly form an association to an English word for each syllable. The association rates (i.e., low, 
Four FAILURES to DEMONSTRATE THAT SCARCITy MAGNIFIES PREFERENCE FOR FAMILIARITY

medium, and high) are the percentage of the 15 participants who reported forming an association to a syllable. Johnson et al.' (1960) work found that more familiar words (i.e., those more frequently associated with known words) were judged more positively than unfamiliar words.

After rating the names and nonsense syllables, participants completed standard demographic items (race, gender, income, education, subjective SES) and an embedded attention check. All participants were debriefed. Participants who did not follow the manipulation instructions (e.g., copy and paste text from a secondary document instead of describing an experience; $\mathrm{n}=2$ ), yielding a final sample size of 199 participants $\left(\mathrm{n}_{\text {Control }}=103\right.$, $\mathrm{n}_{\text {scarcity }}=96$ ). Participants were paid $\$ 0.75$ for completing the study.

\section{Results \\ Confirmatory Results}

Data were submitted to multilevel models that regressed liking ratings on stimulus familiarity, experimental condition, and their interaction. In

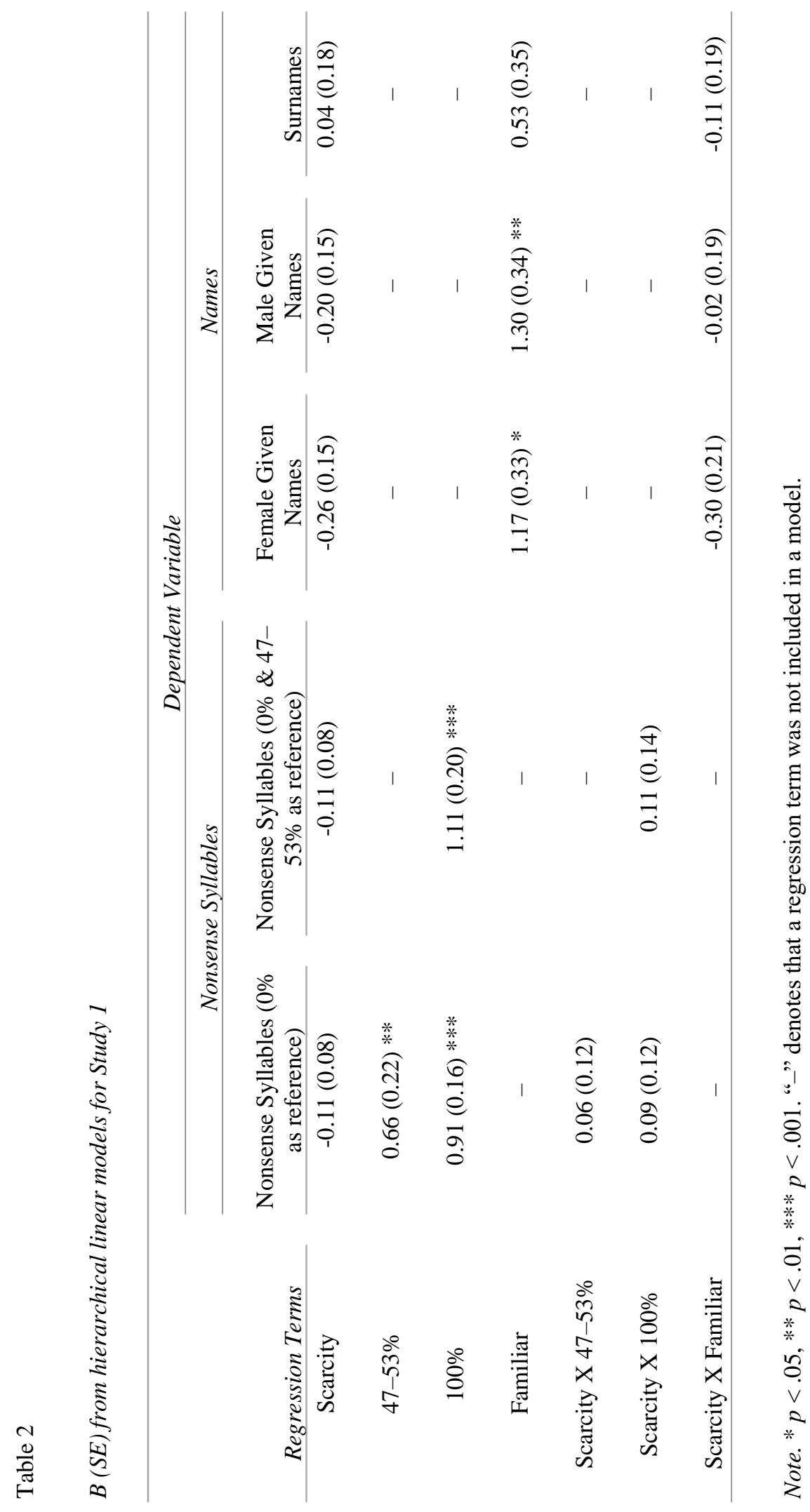




\section{ANTONOPLIS \& CHEN}

addition, all ratings were partitioned into random intercepts within participants and random effects of familiarity within participants. That is, we controlled for the possibility that overall rating patterns might vary across participants and that preferences for familiarity might vary across participants.
We also included random intercepts and slopes for experimental condition within stimuli in order to prevent stimulus-specific effects from impact the overall result. Table 2 shows the multilevel regression results for all dependent variables.
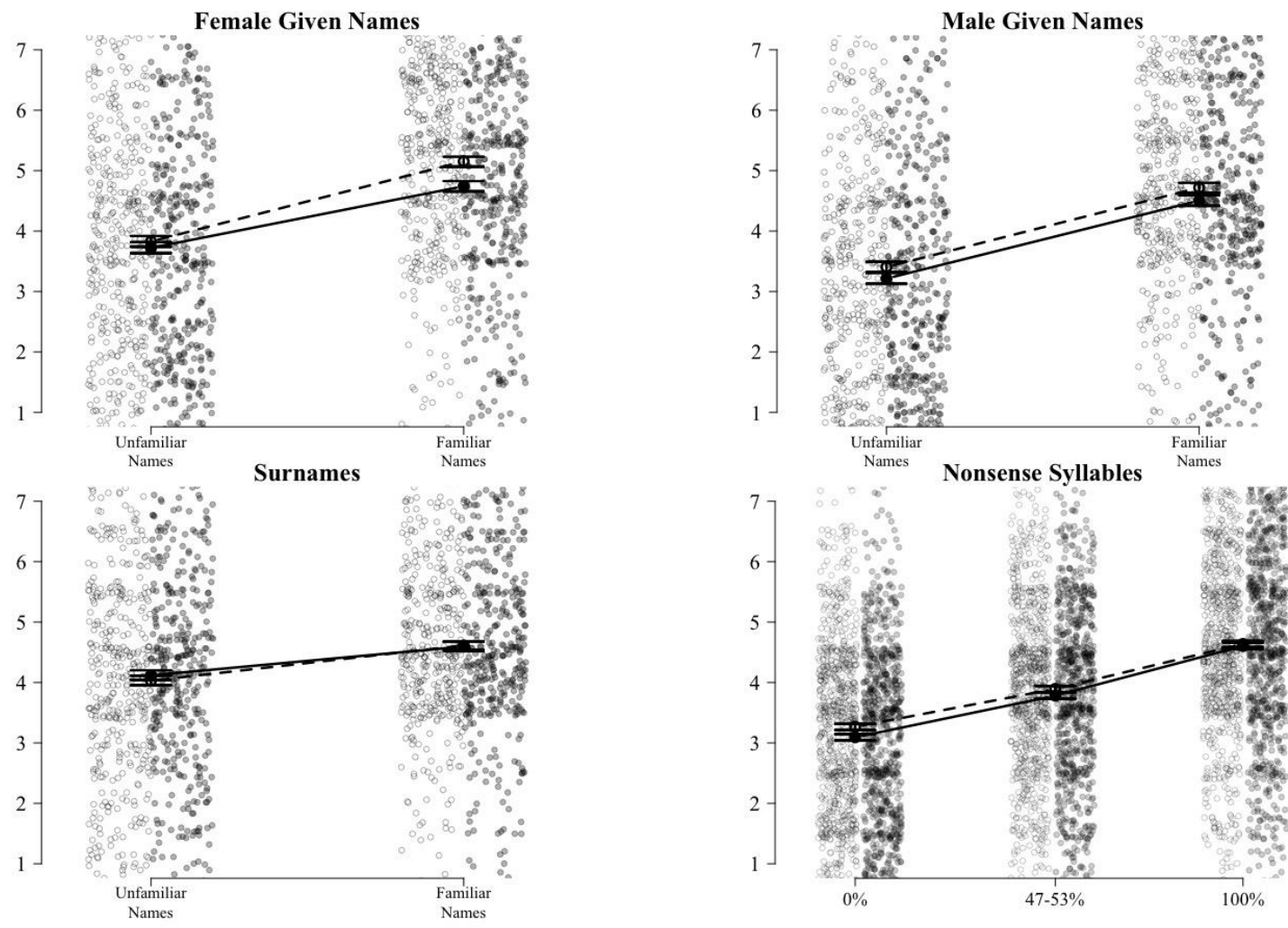

Figure 1. Scarcity condition depicted with filled circles and solid lines; control condition, with hollow circles and dashed lines. All name ratings were in terms of liking $(1=$ dislike, $7=$ like $)$. Syllable ratings were in terms of how bad $(=1)$ or good $(=7)$ participants thought it meant in a foreign language.

As expected, participants rated more familiar given names as more preferable to less familiar given names (females: $B=1.17, t(6.62)=3.57, p=.010$, pseudo- $\mathrm{R}^{2}=.66$; males: $B=1.30, t(6.51)=3.82, p=.008$, pseudo- $\left.\mathrm{R}^{2}=.69\right)$. In addition, relative to low-association syllables, participants rated medium-association syllables as better-sounding $\left(B=0.66, t(22.58)=2.97, p=.007\right.$, pseudo- $\left.\mathrm{R}^{2}=.55\right)$ and highassociation syllables as better-sounding $(B=0.91$, $t(25.43)=5.62, \quad p<.001$, pseudo- $\left.\mathrm{R}^{2}=.28\right)$. High-association syllables were also rated as better-sounding than combined medium- and low-association syllables $(B=1.11$, $t(25.43)=5.62, p<.001$, pseudo- $\left.\mathrm{R}^{2}=.45\right)$. Thus, all of these given name and nonsense syllable stimuli appeared to operate as expected in that they yielded the normative preference for more to less familiar objects. In contrast, preferences did not vary across more and less familiar surnames $\left(B=0.53, t(6.63)=1.50, p=.179\right.$, pseudo- $\left.\mathrm{R}^{2}=.25\right)$, suggesting that the chosen surnames were inappropriate to test our hypothesis. In addition, as expected, there were no main effects of scarcity on ratings ( $B$ 's from -0.26-0.03; $p$ 's from .093-.771; pseudo- ${ }^{2}$ 's from .0004-.04). Recalling an experience of scarcity did not cause participants to rate all stimuli as more or less preferable or good, relative to the control condition. If this main effect had been observed, it might suggest a different psychological effect of scarcity than hypothesized: that it makes people like or dislike any stimuli more on top of any heightened preference contrasts between subsets of stimuli. Thus, our stimuli and scarcity manipulation mostly conformed with our reasoning about how each would function. 
FOUR FAILURES to DEMONSTRATE THAT SCARCITY MAGNIFIES PREFERENCE FOR FAMILIARITY

Table 3

Mean (SD) for unfamiliar and familiar stimuli across two experimental conditions in Study 1

\begin{tabular}{|c|c|c|c|c|c|}
\hline & & \multicolumn{4}{|c|}{ Dependent Variable } \\
\hline \multicolumn{2}{|c|}{ Experimental Condition } & $\begin{array}{l}\text { Nonsense } \\
\text { Syllables }\end{array}$ & $\begin{array}{c}\text { Female Given } \\
\text { Names }\end{array}$ & $\begin{array}{l}\text { Male Given } \\
\text { Names }\end{array}$ & Surnames \\
\hline \multirow[t]{5}{*}{ Control } & $0 \%$ & $3.27(1.43)$ & - & - & - \\
\hline & $47-53 \%$ & $3.89(1.37)$ & - & - & - \\
\hline & $100 \%$ & $4.64(1.48)$ & - & - & - \\
\hline & Unfamiliar & - & $3.83(1.82)$ & $3.41(1.79)$ & $4.03(1.65)$ \\
\hline & Familiar & - & $5.15(1.53)$ & $4.72(1.59)$ & $4.61(1.36)$ \\
\hline \multirow[t]{5}{*}{ Scarcity } & $0 \%$ & $3.09(1.44)$ & - & - & - \\
\hline & $47-53 \%$ & $3.78(1.50)$ & - & - & - \\
\hline & $100 \%$ & $4.60(1.60)$ & - & - & - \\
\hline & Unfamiliar & - & $3.72(1.87)$ & $3.21(1.86)$ & $4.12(1.64)$ \\
\hline & Familiar & - & $4.74(1.66)$ & $4.51(1.64)$ & $4.60(1.46)$ \\
\hline
\end{tabular}

Note. "-" denotes that a regression term was not included in a model. The three levels of nonsense syllables reflect association rates between syllables and English words made by participants $(\mathrm{N}=15)$ reported in Glaze (1928).

Our focal hypothesis - that scarcity would magnify preferences for familiar over unfamiliar objects - did not receive support ( $B$ 's from -0.30-0.11; $p$ 's from .155-.910; pseudo- $\mathrm{R}^{2}$ 's from .00008-.09). Figure 1 shows scatterplots and means across conditions for all dependent variables. Table 3 lists the means and standard deviations of ratings for each group and dependent variable. In general, means are quite consistent across experimental groups. Any apparent moderation of ratings by experimental group appears to come from participants in the scarcity condition disliking unfamiliar objects more, rather than liking familiar options more. In fact, participants in the control condition typically reported more liking of familiar objects than those in the scarcity condition.

\section{Exploratory Results}

What proportion of participants preferred familiarity?. Following a reviewer's suggestion, we checked the proportion of participants whose personal preferences for familiarity matched the normative preference. To do so, we examined the distribution of random effects of familiarity, calculating the percentage of participants with a random effect greater than 0 . After that, we re-ran the models using only participants whose personal preference matched the normative preference. We did this for all four outcomes. Across all outcomes, a majority of participants' personal preferences matched the normative preference for familiar over unfamiliar stimuli (from 77\%$96 \%$ ). Subgroup analyses examining only participants who preferred familiar over unfamiliar stimuli did not yield 


\section{ANTONOPLIS \& CHEN}

substantively different results from the main analyses. The critical interaction between familiarity and scarcity remained non-significant ( $p$ 's from .149-.879). These results suggest that focusing on individual versus normative preference for familiarity does not explain our null results.

Bootstrapped equivalence test. Though results were inconsistent with our hypothesis, failure to reject a null hypothesis is not equivalent to demonstrating evidence in favor of the null. To argue in favor of the null, one would need to show that results are more consistent with some prior belief about the distribution of data (i.e., Bayesian analysis) or show that the observed effect falls outside the range of effect sizes one considers worth studying (i.e., smallest effect size of interest in equivalence tests). We did not have a strong prior about the effect size or a smallest effect size of interest, so instead we bootstrapped effect sizes (R2's) for the key interaction test for our four outcome variables. The bootstrapped estimate and confidence intervals provide a sense of what the true effect is likely to be, and other researchers may decide whether effects in this range are worth pursuing. We started the bootstrapping using the full models from the confirmatory hypothesis tests. If models consistently failed to converge, random effects were dropped until the models consistently converged. This process resulted in dropping random effects of experimental condition and stimulus familiarity for the surnames outcome and all pairwise comparisons between syllables outcomes.

For surnames the average $\mathrm{R}^{2}$ was .002 , 95\% CI [1.76e$6, .01]$; for female given names, .11, 95\% CI [2e-4,.36]; for male given names, $.04,95 \%$ CI $[3.75 \mathrm{e}-5, .18]$; high versus low syllables, $.0005,95 \%$ CI [4.98e-7,.002]; medium versus low syllables, .0002, $95 \%$ CI [1.59e-7,7e-4]; and high versus medium and low syllables, .001, 95\% CI [1.24e-6,.005]. Clearly, the inclusion or exclusion of random effects made a large difference in the estimates and confidence intervals. Outcomes with simpler models indicated that the key interaction was unlikely to account for very much variance at all. Outcomes with the full model (i.e., female and male given names) indicated that the key interaction could account for very little variance or a considerable portion of the variance. These results suggest that our samples were not sufficiently powered to estimate the interaction's effect size using the full model.

\section{Discussion}

Recalling an experience of scarcity, versus a negative experience, did not make participants more strongly prefer familiar to unfamiliar objects. These results do not appear to have happened because of poor stimulus selection or alternative psychological processes of scarcity. All but one set of stimuli successfully recreated the normative preference for familiarity, and overall rating patterns did not vary across experimental conditions. In addition, manual inspection of written responses to the manipulation showed that most participants (99\%) wrote a relevant response. It is possible that our manipulation did not work, but our lack of a manipulation check prevents probing this possibility. The manipulation has previously been found to successfully manipulate felt scarcity in the same population we used (Roux et al., 2015) and follows the format of other successful manipulations of broad social constructs and mindsets (e.g., social power; Galinsky, Gruenfeld, \& Magee, 2003; Kraus, Chen, \& Keltner, 2011). Hence, though a different manipulation of scarcity might better test our hypothesis, the present results seem more consistent with the null hypothesis.

In the following studies, we tested whether alternative manipulations of scarcity may produce our predicted effect. We also tested the possibility that the stimuli we usednames and nonsense syllables - are inappropriate stimuli for testing our hypothesis. Finally, we tested whether the predicted effect is inappropriate to be tested with brief experimental methods (e.g., the effect unfurls over time) and instead better tested with an individual-difference approach.

\section{Study 2: A Different Manipulation of Scarcity}

After finishing Study 1, we became aware of a study by Litt, Reich, Maymin, and Shiv (2011) that claimed to show our effect of interest. In two studies, the authors found that, under increased time pressure, participants were more likely to select a strategy associated with a stimulus they had previously been made more familiar with (i.e., an incidentally familiar strategy), even though the more familiar strategy was less helpful for their goal completion. Based on these results, the authors concluded that scarcity (here, of time) increased preference for familiarity. However, by varying the utility of strategies for goal completion, the authors added a factor to their design, a factor for which they did not test all levels. The authors studied only the condition where the familiar is less helpful than the unfamiliar (familiar < unfamiliar), not where the two are equal in helpfulness (familiar $=$ unfamiliar) or familiar is more helpful than unfamiliar (familiar > unfamiliar). Thus, the studies do not indicate what the baseline preference for familiarity is across different utilities and whether the difference observed in the reported studies results from time pressure increasing preference for familiarity or lack of time pressure opening people up to the unfamiliar when it is more helpful. These studies demonstrate only that under different amounts of time pressure participants, on average, preferred a more familiar object at different rates. They do not provide information on whether participants' behavior under time pressure represents a deviation from standard rates of preference for familiarity.

To fully understand whether scarcity increases preference for the familiar, we conducted a similar study to Litt et al. (2011) that examined choices across all possible utilities (i.e., familiar > unfamiliar, familiar = unfamiliar, familiar < unfamiliar). In particular, we adapted the general 
experimental design of manipulating scarcity (here, as financial pressure, instead of as time pressure), the familiarity of possible strategies for completing the target goal (here, as given names, instead of as primed familiarity), and the degree of helpfulness of possible strategies (here, where the more familiar strategy could be more, equal, or less helpful, instead of only less helpful). Thus, this study should not be considered a replication of Litt et al. (2011) but instead a conceptual replication and extension (LeBel et al., 2019). The pre-registration form, study materials, and data are available here: https://osf.io/2tykn/.

\section{Method}

After designing the experiment, we, the authors, disagreed about the likelihood it would show the hypothesized effect and so devised a stopping rule for participation based on how much money we were willing to spend on the study. We decided to first collect data from 66 participants (33 participants per between-subjects condition); inspect the condition means; and if the means were in the hypothesized order, proceed to collect data until we reached our informal lab standard of 100 participants per between-subjects condition.

In total, 66 participants were recruited from Amazon's Mechanical Turk and paid \$0.40 for completing a 4-minute study. Their demographic characteristics matched typical samples on MTurk (mostly White, mostly men, in their mid30 's, had some amount of college education, and earning a relatively low income; Buhrmester et al., 2011) and are reported in full in Table 1. After consenting to participate, participants were randomly assigned to a scarcity or control manipulation. Participants then read a passage instructing them to imagine a hypothetical scenario for one minute. In the scarcity condition, participants read the following passage, similar to other passages used to manipulate scarcity (e.g., Mani et al., 2013):

You're short for rent this month. You need about $\$ 1,000$ to make it. Imagine you have the opportunity to win this amount by playing some small bets online. You are offered six bets, but they are paired up into three pairs-and you have only enough money to choose one of the bets in each pair, for a total of three bets. Whichever three you play, winning all three guarantees you at least $\$ 1,000$. The bets are presented on the following pages. Which three do you choose?

Participants in the control condition read the following passage, which we designed to trigger a sense of abundance or non-scarcity:

Every few months you like to play some small bets online and treat yourself to something nice with whatever you win. Imagine that this month, you're offered six bets, but they are paired up into three pairs - and you can only choose one of the bets in each pair, for a total of three bets. Whichever three you play, winning all three guarantees you at least $\$ 1,000$. The bets are presented on the following pages. Which three do you choose?

An embedded, invisible timer in the page required participants to spend at least thirty seconds reading and imagining the passage they were shown. After thirty seconds had passed, participants could advance to the next screen where they were presented with three pairs of bets.

The bets asked participants to guess the rank of a male or female given name's frequency of assignment within \pm 20 positions across all US newborns in the next calendar year. The names used were the same as in Study 1 (familiar: Isabella, Sophia, Emma, Olivia, Jacob, Ethan, Michael, William; unfamiliar: Lilith, Charleigh, Dania, Savannah, Truman, Eliezer, Reuben, Bailey). For each pair of bets, participants saw a new pair of names, always chosen so that one was familiar and the other, unfamiliar. In total, each subject saw six of 16 possible names. Within each pair of bets, names were matched on gender. Participants were randomly assigned to see three female pairs, two female pairs and one male pair, one female pair and two male pairs, or three male pairs. Thus, for two participants that saw two female pairs and one male pair, one subject could see \{Isabella vs. Lilith, Sophia vs. Charleigh, Jacob vs, Truman\} and the other, \{Sophia vs. Dania, Olivia vs. Savannah, Michael vs. Bailey\}. Each pair of names was randomly assigned to one of the three pay rates (familiar > unfamiliar, familiar = unfamiliar, familiar $<$ unfamiliar), and the order in which the three pay rates were presented was randomized for each participant. This degree of randomization was necessary to remove any potential order or pairing confounds from the results.

Each pair of bets was presented as follows:

Which do you play? (Both names are in the top 1000 most popular names.):

Earn [\$400, \$450, \$350] if you guess the rank, somewhere between 1 and 1000, of the name [familiar name] relative to other names given to US newborns next year (within 20 rank positions).

Earn [\$400, \$350, \$450] if you guess the rank, somewhere between 1 and 1000, of the name [unfamiliar name] relative to other names given to US newborns next year (within 20 rank positions).

All possible combinations of winnings totaled more than $\$ 1000$, as indicated in the initial instructions participants $\operatorname{read}(\$ 400+\$ 450+\$ 350=\$ 1200 ; \$ 400+\$ 450+\$ 450=$ $\$ 1300 ; \$ 400+\$ 350+\$ 350=\$ 1100)$. Totals from winning all three bets were equal if a subject chose all the familiar $(\$ 400+\$ 450+\$ 350=\$ 1200)$ or all the unfamiliar bets $(\$ 400+\$ 350+\$ 450=\$ 1200)$, so there was no monetary incentive to prefer one over the other.

After selecting the three bets they would play, participants completed the same demographic items as in Study 1 (race, gender, education, income, subjective SES) and an embedded check (i.e., "Please select 'Strongly Agree' for this item."). Following our pre-registration, participants 
who failed the attention check were removed from all analyses $(n=2)$, leaving a final sample size of $64\left(n_{\text {Control }}=32\right.$, $\left.\mathrm{n}_{\text {Scarcity }}=32\right)$.

\section{Results}

As pre-registered, after collecting data from sixty-six participants, we inspected means across conditions to determine whether participants' choices were in the predicted directions. Overall, participants favored to bet on the more familiar option, even when it was worth less than the unfamiliar option. Figure 2 plots means and standard errors of choice across experimental condition and bet payout. Contrary to our hypothesis that scarcity would increase preference for familiarity, participants in the scarcity condition appeared to less strongly prefer the familiar option across all bets (scarcity: $\mathrm{M}_{\text {ChooseFamiliar }}=2.06$, $\mathrm{SD}=0.91$; control: $\mathrm{M}_{\text {ChooseFamiliar }}=2.31, \mathrm{SD}=0.82$ ) and to show a stronger decline in preference for the familiar bet across payouts (scarcity: from $84 \%$ choosing familiar in familiar > unfamiliar to $53 \%$ choosing familiar in familiar < unfamiliar; control: from $88 \%$ choosing familiar in familiar $>$ unfamiliar to $59 \%$ choosing familiar in familiar < unfamiliar). Based on these patterns and our pre-registration, we ceased data collection.

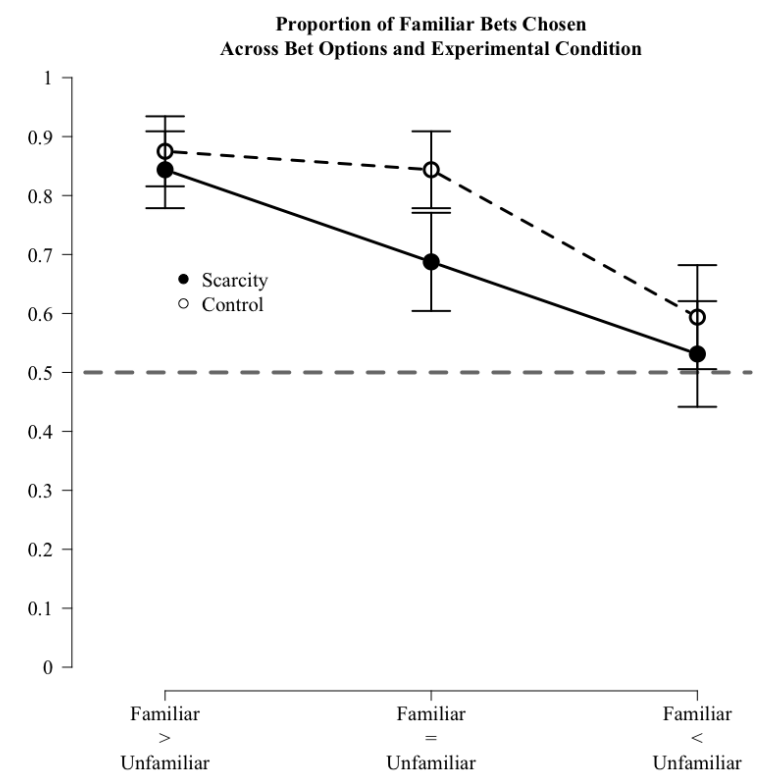

Figure 2. Bars are standard errors.

\section{Exploratory Analyses}

Planned analyses. Per a reviewer's suggestion, we conducted our planned statistical analyses on the data from 64 participants. Following the qualitative inspection, participants, on average, preferred the familiar bet to the unfamiliar bet across all conditions $(B=3.33, z=3.72, p<.001$, $O R=27.94,95 \%$ CI $[4.83,161.49)$. This preference was not significantly stronger in the control versus scarcity condition
$(B=-0.73, z=-0.61, p=.541, O R=0.48,95 \%$ CI $[0.05,5.02])$, and it varied linearly across the bet worth conditions such that the familiar option was chosen most often when it was worth more than the unfamiliar option and less often when the two were equal in value or the unfamiliar option was worth more $(B=-1.00, z=-3.01, p=.003, O R=0.37,95 \%$ CI $[0.19,0.71])$. Finally, the interaction between scarcity versus control condition and bet worth was not significant $(B=0.08$, $z=0.17, p=.866, O R=1.09,95 \%$ CI $[0.41,2.85])$, suggesting that the scarcity condition did not make participants more strongly prefer familiarity even when it was not in their interest to prefer familiarity.

What proportion of participants preferred familiarity?. Following Study 1, we checked the proportion of participants whose personal preferences for familiarity matched the normative preference and re-ran the main analyses using only these participants. One hundred percent of participants showed the normative preference in their personal preferences. Hence, restricting analyses did not eliminate any deviant participants, and results remained as reported above, suggesting that scarcity did not make participants more strongly prefer familiarity when it was not in their interest to prefer familiarity.

Equivalence test. The odds-ratio effect size $(O R=1.09)$ and its $95 \%$ confidence interval $([0.41,2.85])$ for the interaction between scarcity and familiarity from the full model provide a simple check of what effect sizes can be ruled out from the present data. The confidence interval covers a very large range of effect sizes, including both very large negative effects (lower bound of 0.41), indicating that, on average, participants in the scarcity condition less heavily favored the familiar bet relative to participants in the control condition as its worth decreased), and very large positive effects (upper bound of 2.85), indicating that, on average, participants in the scarcity condition more heavily favored the familiar bet relative to participants in the control condition as its worth decreased). Thus, these results are not very informative about the range of effect sizes that can plausibly be ruled out. This is to be expected from the small sample size.

\section{Discussion}

As in Study 1, we failed to reject the null hypothesis per the conditions stipulated in our pre-registration. Thus, we again failed to demonstrate that scarcity magnifies the preference for familiarity. Admittedly, our manipulation was slightly non-intuitive and lacked high ecological validity (who is short on rent but has enough money to place somewhat large bets?), and that may have impacted results. Despite this, it was internally valid in that the names used showed the expected familiarity bias. Moreover, being short on rent was a common scarcity experience described in the written responses to Study 1's manipulation of scarcity. Perhaps the problem emanated from our control condition, winning extra money for a treat. But given that participants 


\section{Four FAILURES To DEMONSTRATE THAT SCARCITy MAGNIFIES PREFERENCE FOR FAMILIARITY}

in Study 1 considered being short on money for critical things (e.g., rent, textbooks, medical expenses) to be experiences of scarcity, trying to win money for a nonessential luxury experience (a treat) would seem to be a good conceptual opposite of what MTurkers consider experiences of scarcity. As we did not include a manipulation check, it is not possible to test how well the manipulation induced scarcity for participants. Another possibility is that our stimuli are inappropriate. Maybe our hypothesized effect occurs for only a subset of all possible stimuli, and given names lie outside that subset. Though we weren't sure what that subset would be, the stimuli used in Zhu and Ratner (2015), who showed that scarcity magnifies individual preferences, would appear to be appropriate. Hence, we adapted an experimental design from Zhu and Ratner (2015) for a subsequent study.

\section{Study 3: Alternative Stimuli}

Having observed two non-significant results, we thought it best to try a manipulation from the study that reported the result inspiring our study. Perhaps, the two manipulations of scarcity we had used, though apparently valid in prior work, were inappropriate for our research question. In addition, the stimuli we used may have been inappropriate, whereas stimuli from the original report should be appropriate. Hence, we adapted the experimental design of Study 1 from Zhu and Ratner (2015). In particular, we used the same "buying groceries at the market" paradigm (described further below) and altered the kinds of groceries available in order to match our theoretical question (described further below). Thus, as stated in the Introduction, this study should not be considered a replication of Zhu and Ratner (2015), but instead a generalizability study to normative preferences for familiarity (LeBel et al., 2019). The pre-registration form, study materials, and data are available here: https://osf.io/4nxrb/.

\section{Method}

Zhu and Ratner (2015) used the following procedure: First, participants were asked to report their preferences for four flavors of yogurt (as a rank order and rating scale from $0=$ not at all to $100=$ very much). Participants were then asked to imagine they were shopping for groceries and encountered a "Pick Any 4 Yogurts for \$1" sale on yogurt. Participants were randomly assigned to one of two conditions: resource scarcity, wherein only four of each yogurt flavor was available, or resource abundance, wherein forty of each yogurt flavor remained. Finally, participants selected how much of each flavor they wanted. Examining differences between participants favorite (=rank 1) and non-favorite yogurts (=all other ranks), Zhu and Ratner (2015) found that participants in the scarcity, versus abundance, condition reported a larger difference between their favorite and nonfavorite flavors for both liking and share of chosen yogurts.

We altered this procedure as follows: First, we used fruits as stimuli, rather than yogurt flavors, as information on fruit familiarity, but not yogurt flavor familiarity, was available. Second, we did not ask participants for their preferences regarding the fruit prior to the manipulation but instead selected fruit to vary in their normatively defined familiarity. We describe the experiment in greater detail below.

Whereas our lab normally collects 100 participants per between-subjects, we decided to increase the number to 150 for the added statistical power. Thus, we recruited three hundred participants from Amazon's Mechanical Turk (paying \$0.25 for a two-minute study). Their demographic characteristics matched typical samples on MTurk (mostly White, in their mid-30's, had some amount of college education, and earning a relatively low income; Buhrmester et al., 2011) and are reported in full in Table 1. As we did not have a readily available dataset of yogurt flavor consumption or production, we used fruit as stimuli instead of yogurt flavors. We thought the use of fruit was justified because they are a kind of food typically consumed as a snack, like yogurt, and are considered healthy, like yogurt. In addition, Zhu and Ratner (2015) used a variety of stimuli, both food and non-food, with no apparent heterogeneity in effect presence. Because we wanted to examine whether the effect extended to nomothetic preferences, we did not ask participants for their fruit preferences before choosing. Instead, we chose fruit that varied in normative familiarity.

We selected fruit based on the amount consumed in the US per year (USDA, 2016), how highly ranked they were according to online ranking websites ("Delicious" from Ranker.com, 2018; "Favorites" from TheTopTens.com, 2018a; "Delicious" from TheTopTens.com, 2018b), and the average calories per serving of each fruit (USDA, 2016). In addition, we also sought to select fruit that would be similarly easy to eat (e.g., whether need to wash before eating, whether need to peel skin off to eat). Based on these criteria, we selected apples and bananas as the more familiar fruit and oranges and peaches as the less familiar fruit. Data for all the fruit we considered are shown in Table 4 . The fruit considered for the study were constrained by the kinds of fruit on which the USDA provided data. We considered all fruit for which the USDA provided data (except lemons, which are rarely eaten as a snack in the US, where the study was conducted).

Following Zhu and Ratner (2015), participants were told they were going to the grocery store to buy some snacks for the day, and that there was a sale on fruit at the grocery store. The grocery store was allowing customers to buy four fruit consisting of any combination of apples, bananas, peaches, and oranges for $\$ 1$. Customers could buy four apples for $\$ 1$; two bananas and two peaches for $\$ 1$; one of each fruit for $\$ 1$; or any other combination of the four fruit for $\$ 1$. The conditions participants had been randomly assigned to varied 
ANTONOPLIS \& CHEN

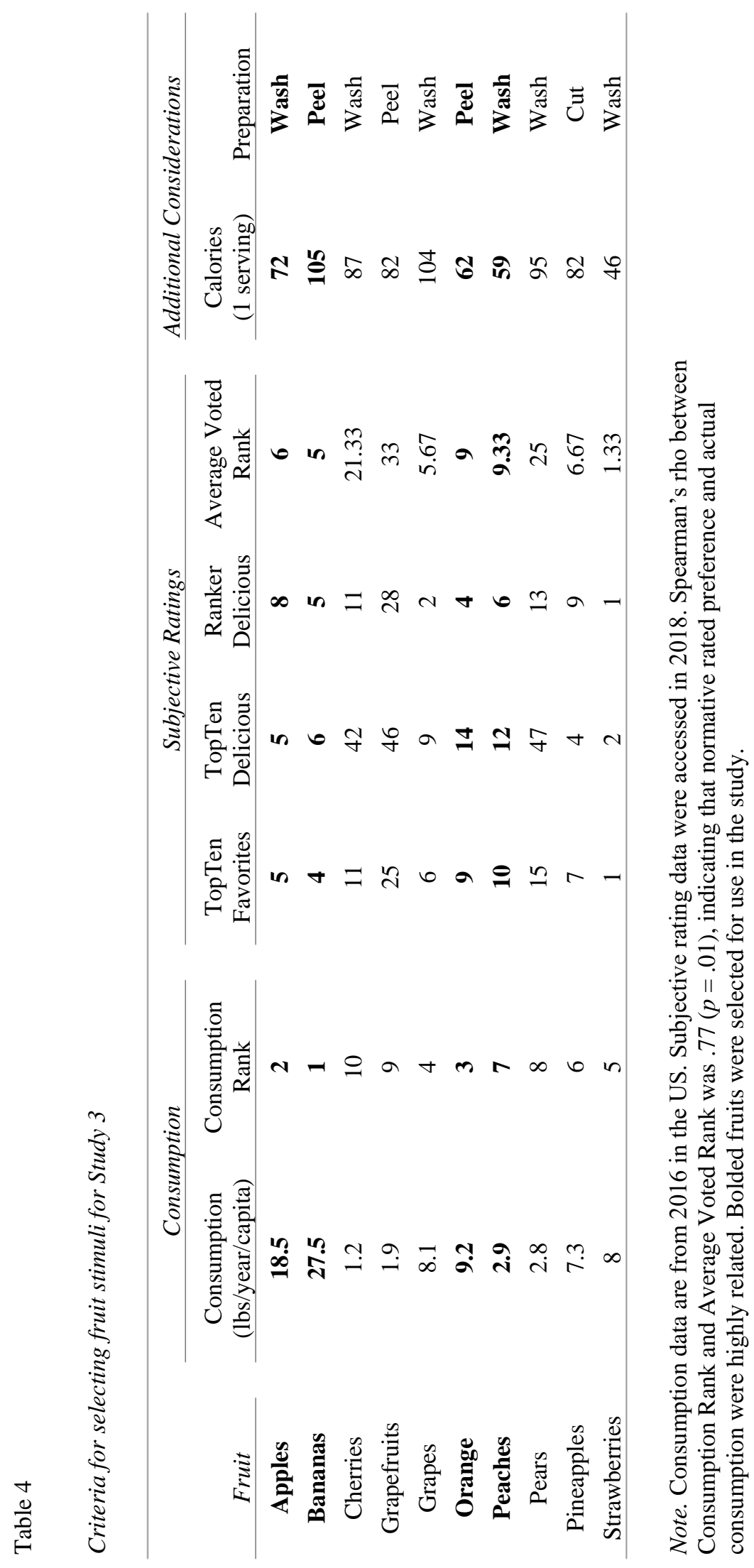


by the amount of fruit available. In the scarcity condition, there were only four of each fruit available. In the control condition, there were 40 of each fruit available. Participants indicated how many of each fruit they wanted by writing a number from one to four in empty boxes next to each fruit. The experiment was programmed such that only numbers could be entered into the boxes, and participants could not progress in the experiment if the sum of numbers entered did not equal four.

After indicating their choices, participants completed an instructional manipulation check ("In the scenario you just read, about how many of each kind of fruit were available at the grocery store" with $\leq 5,10-20$, and $>35$ as possible responses) and reported demographic characteristics (income, MacArthur Ladder, education, race, gender) and an attention check embedded in the demographics section (e.g., "Please selected 'Strongly Agree' for this item."). Per our pre-registration, participants who failed the attention check $(n=10)$ or answered the instructional check incorrectly based on their experimental condition $(n=41)$ were excluded from all analyses. These exclusions reduced the final sample size to 249 individuals $\left(\mathrm{n}_{\text {Control }}=108, \mathrm{n}_{\text {Scarcity }}=141\right)$.

\section{Results}

\section{Confirmatory Results}

Due to the clustered nature of our data, we used a multilevel model for analysis. Participants' fruit choices were regressed on scarcity condition $(=1$; dummy-coded), whether a fruit was familiar (=1; dummy-coded), and their interaction. We included random intercepts and random slopes of fruit familiarity within participants, and random intercepts and random slopes of experimental condition within fruits (following the logic of Study 1). Note that the random effects within fruits depart from the preregistration's specification of only random effects within participants. We made an error in the pre-registration and report the more appropriate model here (though exclusion of random effects within fruits does not change the results). We further departed from the pre-registration by using a Gaussian, instead of binomial, distribution. The dependent variable is a count variable, so a binomial distribution would have been impossible to use. We did not use a Poisson distribution because our data violate a key assumption of it: that the variable is unbounded. Participants could not select more than four of any kind of fruit.

As expected, participants chose more familiar $(\mathrm{M}=1.20$, $\mathrm{SD}=1.02)$ than unfamiliar fruit $(\mathrm{M}=0.80, \mathrm{SD}=0.99), B=0.40$, $t(4.88)=4.62, p=.006$, pseudo- $\mathrm{R}^{2}=.82$. In addition, the scarcity condition did not affect mean fruit choices across conditions (scarcity: $\mathrm{M}=1.00, \mathrm{SD}=1.08$; control: $\mathrm{M}=1.00$, $\mathrm{SD}=0.95), B=0.00, t(184.7)=0.00, p=1.00$, pseudo- $\mathrm{R}^{2}=.00$. Contrary to our hypothesis, preference for familiar fruit was not stronger in the scarcity than control condition, $B=-0.02$, $t(184.9)=-0.16, p=.875$, pseudo- $\mathrm{R}^{2}=.0001$. Consistent with Study 1, participants showed nearly identical preferences for familiar (scarcity: $\mathrm{M}=1.19, \mathrm{SD}=1.05$; control: $\mathrm{M}=1.20$, $\mathrm{SD}=0.98$ ) over unfamiliar fruits (scarcity: $\mathrm{M}=0.81$, $\mathrm{SD}=1.07$; control: $\mathrm{M}=0.80, \mathrm{SD}=0.88$ ) across our two experimental conditions. Figure 3 displays these results.

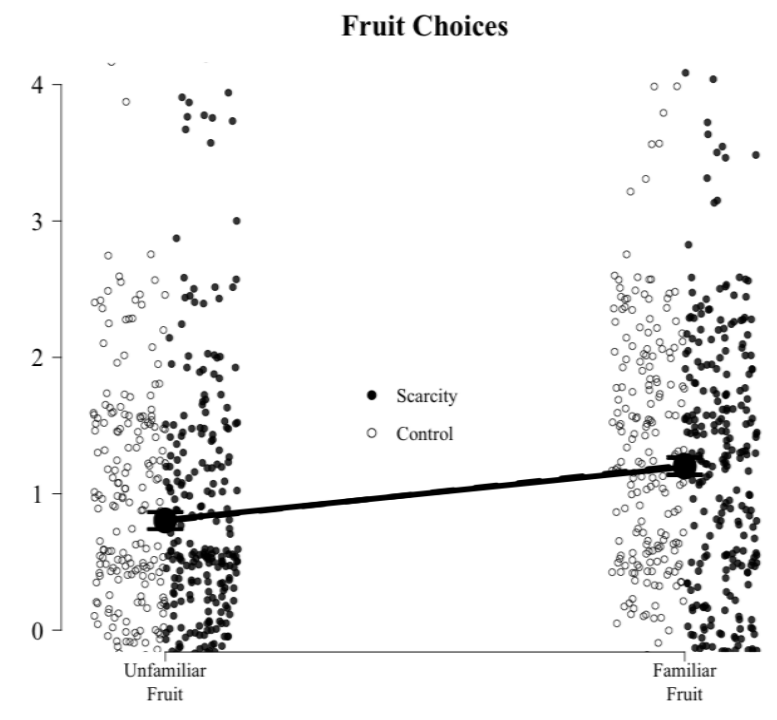

Figure 3. Bars are standard errors.

\section{Exploratory Results}

What proportion of participants preferred familiarity?. Following Study 1, we checked the proportion of participants whose personal preferences for familiarity matched the normative preference and re-ran the main analyses using only these participants. Eighty-two percent of participants showed the normative preference in their personal preferences. Restricting analyses to participants who showed the normative preference did not substantively change the results. The interaction between scarcity and familiarity remained non-significant $(p=.580)$.

Bootstrapped equivalence test. Following Study 1, we used 5000 bootstrapped resamples to estimate pseudo- $\mathrm{R}^{2}$ values for the key interaction. The mean $\mathrm{R}^{2}$ was $.001,95 \%$ CI [1.62x10-6,.007]. This suggests we can rule out pseudo$\mathrm{R}^{2}$ 's larger than .007 as plausible effect sizes.

\section{Discussion}

In a third experiment, we failed to show that situational scarcity magnifies the preference for familiarity. Based on prior work, our experimental manipulation would appear to be internally valid, and our stimuli clearly are, as they replicated the classic familiarity bias. In addition, our increased sample size allowed us to find that the key interaction between scarcity and familiarity is likely very small, in fact much smaller than typical effect sizes in socialpersonality psychology (Richards et al., 2003). Whereas Studies 1 and 2's results may be explained in terms of methodological issues, the results of Study 3 seem to more 


\section{ANTONOPLIS \& CHEN}

clearly suggest that situationally induced scarcity does not magnify preference for familiarity. Although we cannot rule out that the manipulation did not induce scarcity for participants, as we did not include a manipulation check. Still, one possibility that remains untested is that situationally induced scarcity does not alter familiarity bias, but longer term scarcity does. We tested this possibility in Study 4.

\section{Study 4: Individual Differences}

Whereas the apparent null effects in Studies 1-3 suggest that experimentally induced (i.e., situational) scarcity does not magnify situational preference for familiarity, it remains possible that longer term experiences of scarcity may be correlated with higher preference for familiarity. This would be the case if scarcity's effect on preference for familiarity builds up over time. Then, repeated exposure to scarcity would be necessary in order to observe differences in preference for familiarity. Hence, in a final study, we examined whether individual differences in both perceived time and material scarcity correlated with individual differences in preference for novelty. The pre-registration form, study materials, and data are available here: https://osf.io/spzv4/.

\section{Method \\ Sample}

Data came from the first phase of the Measuring Morality dataset maintained by The Kenan Institute for Ethics at Duke University (available

at https://kenan.ethics.duke.edu/attitudes/resources/measuring -morality/). This was a nationally representative sample of adults in the United States. The full sample includes data from 1,519 individuals (full details of demographics are reported in Table 1). We selected items based on our own assessment of whether they measured our constructs of interest. We pre-registered that we planned to combine the items into general indices but that items might be dropped based on low correlations with other items in the index.

\section{Measures}

To assess perceived material scarcity, we used an index of the following items: "Agree that I just don't have enough money to live the life I would like to live." (code: ppl10018; from 1=strongly agree to 5=strongly disagree; reversescored), "Agree that generally, I live from paycheck to paycheck." (code: ppfs0684; from 1=strongly disagree to 4=strongly agree), "How would you rate your own personal finances these days?" (code: ppfs0679; from 1=excellent to $4=$ poor), and "Are your personal finances getting better these days, or worse?" (code: ppfs0680; 1=better, 2=worse, $3=$ same; recoded so that worse and same switched numerical values, and then reverse-scored). All four items were standardized prior to averaging and showed acceptable internal consistency ( $\alpha=.73)$.

To measure perceived time scarcity, we used an index of the following items: "Agree that life is so busy that I find I have less time to spend with family and friends." (code: ppl10008; from 1=strongly agree to 5=strongly disagree; reverse-scored), "Agree that it is hard for me to find the time to be involved in local/community matters." (code: ppl10009; from 1=strongly agree to 5=strongly disagree; reverse-scored), and "Agree that it is becoming increasingly difficult to find the time to relax and unwind." (code: ppl10012; from 1=strongly agree to 5=strongly disagree; reverse-scored). Although these items differ from canonical manipulations of time scarcity wherein participants have more or less time to complete a task (Shah et al., 2012), we thought that as individual-difference measures of time scarcity they are sufficient. An experience of scarcity occurs when a person lacks sufficient resources to meet a goal or need. Our three items all referred to normatively valued goals: personal relationships, community involvement, and relaxing/leisure. Thus, our items appear to satisfy the basic definition of scarcity (lacking a resource-i.e., time-for valued goals). Moreover, people might vary in the extent to which they value these goals, but that is also true of the small monetary awards typical of lab studies (cf. Shah et al., 2012) and, thus, not unique to our items. All three items were standardized prior to averaging and showed good internal consistency $(\alpha=.81)$.

To measure preference for familiarity, we used the following three items: "I think it is important to do lots of different things in life. I always look for new things to try." (code: SV6; from 1=very much like me to 6=not like me at all), "I often try new brands because I like variety." (code: PPADOPT2; from 1=strongly agree to 5=strongly disagree), and "Agree that I am usually the first of my friends to try new products and services." (code: ppfs0687; from $1=$ strongly disagree to 4=strongly agree). Although we had planned to combine these items into a single index, they showed low internal consistency $(\alpha=.54)$, so we used them as three separate items.

Note that sample sizes vary across hypothesis tests because some questions were not asked to all participants, some participants declined or refused to answer questions, and some participants reported being unsure of their response. We recoded any responses of "Not asked", "Refused", "Not applicable", and "Not sure" as missing because they were not substantive responses.

\section{Results \\ Confirmatory Results}

Checking preference for familiarity. To check that we had selected appropriate items, in addition to their face validity, we examined whether average responses to our three items on preference for familiarity were below the scale midpoint. That is, did participants, on average, think that 
Four FAILURES to DEMONSTRATE THAT SCARCITy MAGNIFIES PREFERENCE FOR FAMILIARITY

"look[ing] for new things to try" was "not like me," disagree that "I often try new brands because I like variety," and disagree that they are the first of their friends to "try new products and services"? Affirmations of these questions would indicate average preferences to avoid novelty, presumably in favor of seeking familiarity. To test these hypotheses, we conducted one-sample t-tests, comparing the sample mean to the scale midpoint ( 3.5 for question 1,3 for question 2, and 2.5 for question 3 ). We used one-tailed tests because we had directional predictions, that sample means would be lower than the scale midpoints.

The mean of question 1 ("I think it is important to do lots of different things in life. I always look for new things to try.") was $3.96(\mathrm{SD}=1.29)$, above the scale midpoint of 3.5 $(p=1.00)$. Questions 2 and 3, however, showed the expected

Table 5 levels. The mean of question 2 ("I often try new brands because I like variety.") was $2.75(\mathrm{SD}=1.14), t(1496)=-8.33$, $p<.001$. The mean of question 3 ("Agree that I am usually the first of my friends to try new products and services.") was $1.94(\mathrm{SD}=0.86), t(1086)=-21.55, p<.001$. Thus, two of the familiarity preference items we selected operated as expected, and one did not.

Scarcity and preference for familiarity. Table 5 displays bivariate correlations between time and material scarcity and the three measures of preference for familiarity. Evidence in favor of our hypothesis would be a statistically significant negative correlation between the scarcity and familiarity measures. No such correlations were obtained. Thus, we failed to reject the null hypothesis across all six hypothesis tests.

Correlations between scarcity and familiarity preference (Study 4)

\begin{tabular}{|c|c|c|c|c|c|c|}
\hline \multirow[b]{3}{*}{ Items for Familiarity Preference } & \multicolumn{6}{|c|}{ Scarcity } \\
\hline & \multicolumn{3}{|c|}{ Time } & \multicolumn{3}{|c|}{ Material } \\
\hline & $r$ & $p$ & $95 \%$ CI & $r$ & $p$ & $95 \% \mathrm{CI}$ \\
\hline $\begin{array}{l}\text { nk it is important to do lots of } \\
\text { erent things in life. I always look for } \\
\text { things to try. }\end{array}$ & .03 & .209 & {$[-.02, .08]$} & -.03 & .212 & {$[-.08, .02]$} \\
\hline ten try new brands because I & .08 & .002 & {$[.03, .13]$} & .02 & .472 & {$[-.03, .07]$} \\
\hline
\end{tabular}

variety.

Agree that I am usually the first of my friends to try new products and services. 


\section{Exploratory Results}

Alternative measures of scarcity. Prior research on scarcity has used traditional measures of social class (e.g., income, "mouths to feed") as indicators of scarcity (i.e., Mani et al., 2013; Shah et al., 2015). The logic supporting this usage is that people with fewer resources in general are also likely to have fewer resources than they need. Hence, we estimated post-hoc correlations between "mouths to feed" (household income / sqrt(family size)) and our three measures of preference for familiarity. Again, scarcity, as "mouths to feed," was uncorrelated with preference for familiarity ( $r$ 's from -.01-.05, $p$ 's from .77-1.00).

What proportion of participants preferred familiarity?. Following Study 1, we checked the proportion of participants whose personal preferences for familiarity matched the normative preference and re-ran the main analyses using only these participants. Thirty-five percent of participants disagreed that it was important to try new things in life. Forty-two percent disagreed that they tried new brands because they like variety. Seventy-five percent disagreed that they were the first of their friends to try new products and services.

Analyzing data for only participants who showed the expected preferences for familiarity, material scarcity was significantly negatively correlated with thinking it is important to try new things in life ( $r=-.09, p=.045, \mathrm{~N}=512)$ and with being the first of one's friends to try new products and services $(r=-.08, p=.030, \mathrm{~N}=818)$, but not with trying new brands because of taste for variety $(r-.00, p=.966$, $\mathrm{N}=619$ ). These results suggest that people experiencing greater material scarcity had a relatively stronger preference for familiarity. However, the p-values were quite high, higher than would be expected if these were true effects (Simonsohn et al., 2014), so we are not entirely sure they are real. Time scarcity was not significantly correlated with thinking it is important to try new things in life $(r=.02$, $p=.614, \mathrm{~N}=497)$ or trying new products and services before one's friends ( $r=.01, p=.681, \mathrm{~N}=797)$, but was significantly positively related to trying new brands because of taste for variety $(r=.09, p=.022, \mathrm{~N}=604)$. That is, people who reported experiencing more time scarcity exhibited a preference for novelty: They were more likely to report trying new brands trying new brands because of taste for variety. If real, this is in the opposite of our predicted direction.

Equivalence test. The correlation effect sizes ( $r$ 's in Table 5) and their 95\% confidence intervals (95\% CI in Table 4) provide a simple check of what effect sizes can be ruled out from the present data. The confidence intervals cover a relatively small range of effect sizes, from $r=-.06$ to $r=.13$. This suggests we can rule out $r$ 's outside of the range of $-.06-.13$ as plausible effect sizes. In addition, relative to other effect sizes in social-personality psychology, these fall near or below the 33rd percentile, suggesting that the effect of scarcity on familiarity, assuming it is not null, is smaller than most effects in social-personality psychology.

\section{Discussion}

Taking an individual differences approach, we found that participants preferred familiarity to novelty and that scarcity, both as time and material scarcity, did not magnify this preference. Consistent with Study 3, an equivalence test suggested that the effect of scarcity on familiarity bias, to the extent that it exists, is very small. These results cohere with our experimental results from Studies 1-3. In aggregate, these results suggest that scarcity does not increase preference for familiarity in states or in longer term attitudes.

\section{General Discussion}

Across four pre-registered studies, we failed to find evidence for the hypothesis that scarcity polarizes preferences for familiarity. Three studies tested this experimentally, using diverse stimuli and manipulations. A fourth tested it using an individual differences approach. Although perhaps surprising given prior research (Zhu \& Ratner, 2015), these null results help identify a potential boundary condition of when scarcity polarizes preferences. In particular, scarcity may yield this effect only at the idiographic level. When people experience scarcity, versus abundance, they may exhibit stronger preferences for things they themselves already like, and not for things that are generally liked across people.

Beyond the possibility that idiographic preferences are key to the predicted effect of scarcity increasing the familiarity bias, why else might we have observed these null results? We do not suspect it is an issue of study design. Poor stimulus selection cannot explain these failures, as we consistently found evidence for a normative preference for familiarity (seven of nine dependent variables showed the effect). In addition, we do not expect that we poorly operationalized scarcity. For one, our operationalizations map onto the definition of scarcity pretty well (e.g., not having enough time or money or options to satisfy all of one's desires). Second, several of our operationalizations of scarcity were used in prior research that found effects of scarcity on psychological outcomes and used manipulation checks to assess the key assumption that they induced an experience or perception of scarcity (with all $p$ 's $<.001$; Litt et al., 2011; Roux et al., 2015; Zhu \& Ratner, 2015). Of course, we cannot fully rule out the possibility that our manipulations may have failed to induce a psychological experience of scarcity, due to our not including manipulation checks. Third, we used both experimental and correlational designs, suggesting the null result is not a feature of study type.

One possible explanation is low power. Studies 3 and 4, which had the largest sample sizes of all of our studies, suggested that the key effect was quite small, to the extent that it existed at all. In particular, Study 3's results suggested that the key effect was a pseudo- $\mathrm{R}^{2}$ of $.001,95 \% \mathrm{CI}$ 
[1.62x10-6,.007], and Study 4's results suggested that the key effect was an $r$ from -.06-.13 ( $\mathrm{R}^{2}$ from .004-.017). None of our studies was designed to detect an effect that small.

To the extent that methodological issues do not explain the null results, a theoretical explanation is possible, too. In particular, it may be the case that scarcity does not have "secondary" effects in the sense that it does not impact thoughts, feelings, or behaviors that are not relevant to the immediate context in which scarcity was experienced. Some recent work on scarcity has begun to suggest that scarcity may not have such "secondary" effects. For instance, Camerer et al. (2018) failed to replicate the finding that a brief experience of scarcity reduced cognitive control on a subsequent, unrelated task (i.e., ego depletion; originally reported as Study 1 in Shah et al., 2012). In response, Shah et al. (2018) replicated every study from their own 2012 paper and found that none of scarcity's secondary effects replicated. These included the aforementioned depletion effect, as well as neglect of future demands and neglect of details helpful for future tasks, but not the immediate task. Shah et al. (2018) did, however, replicate all of the "primary" effects of scarcity (i.e., greater present focus, more overborrowing). These failures to replicate suggest that scarcity's effects may be limited to the immediate situation at hand (e.g., spending more time focusing a shot when one has limited shots) and cease when the situation changes (e.g., considering strategies for future rounds, an unrelated cognitive control task). Given that we studied a secondary effect (the primary effects being typical mediators like stress, arousal, etc.), our hypothesis may have been doomed from the start. Still, at least one version of the hypothesis has received empirical support (i.e., the idiographic approach; Zhu \& Ratner, 2015), so future research should determine the robustness of these original results.

\section{Conclusion}

We failed to find support for the hypothesis that scarcity magnifies the preference for familiarity. These results may help place a boundary on prior work showing similar results (Zhu \& Ratner, 2015). At the very least, they identify for other researchers a hypothesis that is unlikely to be generative or, alternatively, demonstrate several sub-optimal tests of the hypothesis, which future researchers can know to avoid.

\section{Author Contact}

Stephen_Antonoplis, antonoplis@berkeley.edu, Department of Psychology, University of California, Berkeley, CA 94720, U.S.A.

\section{Acknowledgements}

The authors thank members of the Self, Identity, and Relationships lab for their feedback on this project.

\section{Conflict of Interest and Funding}

The authors hold no known conflicts of interest relevant to this work. S. Antonoplis was funded by a NSF Graduate Research Fellowship, Grant Number DGE 1752814.

\section{Author Contributions}

S.A. and S.C. conceived the project and designed the studies jointly. S.A. conducted data analyses and drafted the manuscript, with critical feedback from S.C.

\section{Open Science Practices}

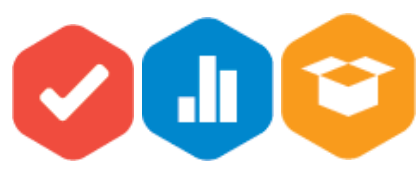

This article earned the Preregistration, Open Data and the Open Materials badge for preregistering the hypothesis and analysis before data collection, and for making the data and materials openly available. It has been verified that the analysis reproduced the results presented in the article. The entire editorial process, including the open reviews, are published in the online supplement.

\section{References}

Bargh, J. A. (1992). Does subliminality matter to social psychology? Awareness of the stimulus versus awareness of its influence. In R.F. Bornstein \& T. S. Pittman (Eds.), Perception without awareness: Cognitive, clinical, and social perspectives (pp. 236255). Guilford Press.

Bornstein, Robert F. (1989). Exposure and Affect: Overview and Meta-Analysis ofResearch, 1968-1987. Psychological Bulletin, 106(2), 265-289.

Buhrmester, M., Kwang, T., \& Gosling, S. D. (2011). Amazon's Mechanical Turk: A New Source of Inexpensive, Yet High-Quality, Data? Perspectives on Psychological Science, 6(1), 3-5. https://doi.org/10.1177/1745691610393980

Camerer, C. F., Dreber, A., Holzmeister, F., Ho, T.-H., Huber, J., Johannesson, M., Kirchler, M., Nave, G., Nosek, B. A., Pfeiffer, T., Altmejd, A., Buttrick, N., Chan, T., Chen, Y., Forsell, E., Gampa, A., Heikensten, E., Hummer, L., Imai, T., ... Wu, H. (2018). Evaluating the replicability of social science 
experiments in Nature and Science between 2010 and 2015. Nature Human Behaviour, 2(9), 637-644. https://doi.org/10.1038/s41562-018-0399-z

Galinsky, A. D., Gruenfeld, D. H., \& Magee, J. C. (2003). From Power to Action. Journal of Personality and Social Psychology, 85(3), 453-466. https://doi.org/10.1037/0022-3514.85.3.453

Gino, F., \& Pierce, L. (2009). The abundance effect: Unethical behavior in the presence of wealth. Organizational Behavior and Human Decision Processes, 109(2), 142-155. https://doi.org/10.1016/j.obhdp.2009.03.003

Glaze, J. A. (1928). The Association Value of Non-Sense Syllables. The Pedagogical Seminary and Journal of Genetic Psychology, 35(2), 255-269. https://doi.org/10.1080/08856559.1928.10532156

Gorn, G., Pham, M. T., \& Sin, L. Y. (2001). When arousal influences ad evaluation and valence does not (and vice versa). Journal of Consumer Psychology, 11(1), 43-55.

Griskevicius, V., Ackerman, J. M., Cantu, S. M., Delton, A. W., Robertson, T. E., Simpson, J. A., Thompson, M. E., \& Tybur, J. M. (2013). When the Economy Falters, Do People Spend or Save? Responses to Resource Scarcity Depend on Childhood Environments. Psychological Science, 24(2), 197-205. https://doi.org/10.1177/0956797612451471

Johnson, R. C., Thomson, C. W., \& Frincke, G. (1960). Word values, word frequency, and visual duration thresholds. Psychological Review, 67(5), 332.

Kraus, M. W., Chen, S., \& Keltner, D. (2011). The power to be me: Power elevates self-concept consistency and authenticity. Journal of Experimental Social Psychology, 47(5), 974-980. https://doi.org/10.1016/j.jesp.2011.03.017

LeBel, E. P., Vanpaemel, W., Cheung, I., \& Campbell, L. (2019). A Brief Guide to Evaluate Replications. MetaPsychology, 3, 9.

Litt, A., Reich, T., Maymin, S., \& Shiv, B. (2011). Pressure and Perverse Flights to Familiarity. Psychological Science, 22(4), 523-531. https://doi.org/10.1177/0956797611400095

Mani, A., Mullainathan, S., Shafir, E., \& Zhao, J. (2013). Poverty impedes cognitive function. Science, 341(6149), 976-980.

Mano, H. (1992). Judgments under distress: Assessing the role of unpleasantness and arousal in judgment formation. Organizational Behavior and Human Decision Processes, 52(2), 216-245.

Mano, H. (1994). Risk-taking, framing effects, and affect. Organizational Behavior and Human Decision Processes, 57, 38-58.

Montoya, R. M., Horton, R. S., Vevea, J. L., Citkowicz, M., \& Lauber, E. A. (2017). A re-examination of the mere exposure effect: The influence of repeated exposure on recognition, familiarity, and liking. Psychological Bulletin, 143(5), 459-498. https://doi.org/10.1037/bul0000085

Mullainathan, S., \& Shafir, E. (2013). Scarcity: Why having too little means so much. Times Books/Henry Holt and Co.

Muthukrishnan, A. V., Wathieu, L., \& Xu, A. J. (2009). Ambiguity Aversion and the Preference for Established Brands. Management Science, 55(12), 1933-1941. https://doi.org/10.1287/mnsc.1090.1087

Oppenheimer, D. M. (2004). Spontaneous discounting of availability in frequency judgment tasks. Psychological Science, 15(2), 100-105.

Piketty, T. (2014). Capital in the Twenty-First Century. Harvard University Press.

R Core Team. (2019). R: A language and environment for statistical computing. R Foundation for Statistical Computing. https://www.R-project.org/

Ranker.com. (2018). The Most Delicious Fruits. https://www.ranker.com/list/most-deliciousfruits/analise.dubner

Roux, C., Goldsmith, K., \& Bonezzi, A. (2015). On the Psychology of Scarcity: When Reminders of Resource Scarcity Promote Selfish (and Generous) Behavior. Journal of Consumer Research, ucv048. https://doi.org/10.1093/jcr/ucv048

Shah, A. K., Mullainathan, S., \& Shafir, E. (2012). Some Consequences of Having Too Little. Science, 338(6107), 682-685. https://doi.org/10.1126/science. 1222426

Shah, Anuj K, Mullainathan, S., \& Shafir, E. (2018). An exercise in self-replication: Replicating Shah, Mullainathan, and Shafir (2012). 15.

Shah, Anuj K., Shafir, E., \& Mullainathan, S. (2015). Scarcity frames value. Psychological Science, 26(4), 402-412.

Simonsohn, U., Nelson, L. D., \& Simmons, J. P. (2014). PCurve: A Key to the File-Drawer. Journal of Experimental Psychology: General, 143(2), 534-547.

TheTopTens.com. (2018a). Top Ten Favorite Fruits. https://www.thetoptens.com/favorite-fruits/

TheTopTens.com. (2018b). Top Ten Most Delicious Fruits. https://www.thetoptens.com/most-delicious-fruits/

USDA. (2016). Fruit and Tree Nut Yearbook Tables. https://www.ers.usda.gov/data-products/fruit-and-treenut-data/fruit-and-tree-nut-yearbooktables/\#Supply\%20and\%20Utilization

Zajonc, R. B. (1968). Attitudinal effects of mere exposure. Journal of Personality and Social Psychology, 9(2p2), 1.

Zajonc, R. B. (2001). Mere Exposure: A Gateway to the Subliminal. Current Directions in Psychological Science, 10(6), 224-228.

Zhu, M., \& Ratner, R. K. (2015). Scarcity Polarizes Preferences: The Impact on Choice Among Multiple 
FOUR FAILURES to DEMONSTRATE THAT SCARCITY MAGNIFIES PREFERENCE FOR FAMILIARITY

Items in a Product Class. Journal of Marketing

Research, 52(1), 13-26.

https://doi.org/10.1509/jmr.13.0451 